\title{
Transient Effects of Calf Muscle Fatigue and Visual Control on Postural Balance During Single Leg Standing \\ Jin-Tae $\operatorname{Han}^{\dagger}$ \\ Dept. of Physical Therapy, Kyungsung University
}

Received: July 17, 2017 / Revised: July 19, 2017 / Accepted: July 25, 2017

(c) 2017 J Korean Soc Phys Med

\section{| Abstract |}

PURPOSE: Muscle fatigue is a cause to change proprioception. The purpose of this study was to investigate the effects of calf muscle fatigue and visual control on postural balance during single-legged standing in healthy adults.

METHODS: Nineteen healthy adults (male) were participated in this study (mean age: 24.36 years; mean height: $171.32 \mathrm{~cm}$; mean weight: $64.58 \mathrm{~kg}$ ). The postural balance (sway length, sway area, sway velocity of $\mathrm{COG}$ displacement) was measured by Balance Trainer System (BT4) in before and after calf muscle fatigue feeling in single legged stance. In this study, repetitive single-legged heel rise test was used to induce fatigue of the calf muscle. Paired t- test was used to compare the postural balance between before and after calf muscle fatigue. Data of subjects were analyzed using SPSS 22.0 (SPSS Inc., Chicago, IL, USA). Level of significance was set to .05 .

RESULTS: The sway length, sway area, sway velocity of COG (center of gravity) displacement after calf muscle fatigue feeling was significantly increased compared to

$\dagger$ Corresponding Author : jthan2001@ks.ac.kr

This is an Open Access article distributed under the terms of the Creative Commons Attribution Non-Commercial License (http://creativecommons.org/licenses/by-nc/3.0) which permits unrestricted non-commercial use, distribution, and reproduction in any medium, provided the original work is properly cited. before calf muscle fatigue feeling during single leg standing both eye open and close conditions $(\mathrm{p}<.05)$.

CONCLUSION: This study suggested that calf muscle fatigue feeling has affected on postural balance when standing one leg both eye open and close conditions and postural control was disturbed by muscle fatigue and visual feedback in single leg standing.

Key Words: Muscle fatigue, Postural balance, Single leg standing

\section{Introduction}

The muscular fatigue represents an inevitable phenomenon for daily activities (Vuillerme et al., 2002). Muscle fatigue can be defined as a decreased force generating capacity and a transient loss of generated during a maximum voluntary effort (Gandevia, 2001; Allen et al., 2008). Muscle fatigue has been shown to impair postural balance (Gribble and Hertel, 2004), and has altered the position sense at the ankle induced by the muscular fatigue (Forestier et al., 2002). Consequently, it seems reasonable to decrease a postural stability after lower limbs muscular fatigue (Yaggie and Mcgregor, 2002).

Balance can be defined as the ability to maintain the 
vertical projection of the center of mass (COM) on the support surface (Önell, 1999). The ability to maintain the control of the projection of $\mathrm{COM}$ within the postural stability limits during quiet standing has usually been assessed by the use of balance training system or force plate. Increased the trace length, area, velocity of COM are usually interpreted as decreased postural stability or poor balance (Adlerton et al., 2003).

The human calf muscle has been used to study the responses of muscle fatigue (Egana and Green, 2007), and it is an important muscle to study in clinical conditions where its fatigability limits exercise tolerance (Green and Mehlsen, 1999). The calf muscles are important both for stability during standing and for control and propulsion during walking (LaRoche et al., 2010). The calf muscle fatigue could be changed the proprioception (Boucher et al., 2012; Kwon et al., 2013) and the calf muscle strength is important to prevent the falls in older peoples (Maritz and Silbernagel, 2016).

One of interventions for balance training is to maintain a quit standing on a platform while providing visual control (eye open and close conditions) and instructing participants to minimize movement of the COG in quiet standing (Rougier, 2009; Yun and Yoo, 2016). This type of intervention would be effective for reducing postural sway and improving balance control for individuals with muscle weakness (Zijlstra et al., 2010). In addition, Vuillerme et al. (2002) reported that the ability to use visual information for postural balance during bipedal quiet standing following calf muscles fatigue was dependent on the visual target distance.

There is a relationship between calf muscle fatigue and postural balance deficits, but few studies have attempted to compare the postural balance between pre and post calf muscle fatigue both eye open and close conditions during single leg standing. Therefore, the purpose of this study was to investigate the effects of calf muscle fatigue and visual control (eye open and close condition) on postural balance during single leg standing.

\section{Methods}

\section{Subjects}

Nineteen heathy adults (male: 19; age: $24.36 \pm 2.25$ years; weight: $64.58 \pm 7.46 \mathrm{~kg}$; height: $171.32 \pm 6.58 \mathrm{~cm}$ ) with no history of injury or pathology to either lower extremity or visual acuity participated in this study (Vuillerme et al., 2006). All of subjects were fully informed of the procedures and the purpose of this study. Written informed consent was obtained from all subjects prior to the experimental procedure as by the Helsinki declaration.

\section{Apparatus}

A balance trainer system (BT4, Hur-labs, Tampere, Finland) was used to measure the postural balance. BT4 can measure the sway length, sway area, sway velocity of $\mathrm{COG}$ displacements.

\section{Task and procedure}

In this study, repetitive single-legged heel rise test was used to induce fatigue of the calf muscle (Maritz and Silbernagel, 2016). Subjects were asked to perform their dominant heel-lift from neutral foot position to a toestanding position repeatedly as many times as possible. The hip and knee joints were kept fully extended during, repetitive single-legged heel rise test. The aim of this exercise was to induce a muscular fatigue in the ankle plantar-flexor of dominant leg (Adlerton et al., 2003).

Among the postural balance test of BT4 program, Romberg test 30 second was used to measure the sway length, sway area, sway velocity of the COG displacement. Data from BT4 were collected during single-legged standing with arm crossed in front of chest for 30 second before and after calf muscle fatigue. To measure the postural balance at fatiguing condition, the measurements were 
performed immediately after a fatiguing procedure. To prevent the fall during performing tasks, the safety bars were installed on the left and right sides and the subjects were asked to catch the bars if they were going to fall down. The values were measured three times in each experiment, and the average value was used in analysis. The experiment were first performed in eye open condition and following in eye close condition.

\section{Statistical analysis}

Data are represented as means $\pm \mathrm{SD}$. Paired t-test was used to compare the postural balance between pre and post fatigue in single leg standing with eye open and eye close respectively. Data of subjects were analyzed using SPSS 22.0 (SPSS Inc., Chicago, IL, USA). Level of significance was set to .05 .

\section{Results}

In eye open condition, sway length, sway area, sway velocity of COG displacement were significantly increased after calf muscle fatigue feeling compared to those of before calf muscle fatigue feeling $(\mathrm{p}<.05)$ (Table 1). In eye close condition, sway length, sway area, sway velocity of $\mathrm{COG}$ were also significantly increased after calf muscle fatigue feeling compared to those of before calf muscle fatigue feeling $(\mathrm{p}<.05)$ (Table 1). And sway length, sway area, sway velocity of COG with eye close condition were generally increased compared to those with eye open condition.

\section{Discussion}

When muscles are in a fatigued condition, they become less efficient at providing joint stability. Studying about the effects of fatigue on postural control may be possible to examine potential risk factors of musculoskeletal injury related to impaired neuromuscular control (Gribble and Hertel, 2004). Unilateral heel-rise exercise provides a greater load on the calf muscles and is more challenging on the balance (Maritz and Silbernagel, 2016), but this exercise can easily provoke the calf muscle fatigue to disturb the postural balance. The finding of this study indicate that the calf muscle fatigue, as induced with the unilateral heel-rise test, considerably increased sway length, sway area, sway velocity of COG displacement. This could be caused by a decrease of balance coordination resulting from the calf muscle fatigue. Specially, an increase of sway velocity might be caused by faster reaction at ankle joint to maintain the center of gravity during calf muscle fatiguing state. This result was similar to that the postural balance is more closely linked to the velocity of the COG displacement than the amplitude of COG displacement (Adlerton et al., 2003).

Table 1. Comparison of postural balance between before and after calf muscle fatigue feeling during single leg standing $(n=19)$

\begin{tabular}{lccccc}
\hline \multicolumn{1}{c}{ Variables } & Visual condition & Before fatigue feeling & After fatigue feeling & $\mathrm{t}$ & $\mathrm{p}$ \\
\hline \multirow{2}{*}{ Sway length $(\mathrm{mm})$} & Open & $965.32 \pm 218.99$ & $1151.54 \pm 293.57$ & -3.70 & $<.01^{*}$ \\
& Close & $1938.15 \pm 429.88$ & $2145.81 \pm 440.69$ & -2.32 & $.03^{*}$ \\
\hline \multirow{2}{*}{ Sway area $\left(\mathrm{mm}^{2}\right)$} & Open & $633.08 \pm 227.24$ & $819.01 \pm 411.16$ & -2.23 & $.03^{*}$ \\
& Close & $1783.63 \pm 469.34$ & $2126.75 \pm 512.98$ & -2.90 & $<.01^{*}$ \\
\hline \multirow{2}{*}{ Sway velocity } & Open & $32.18 \pm 7.29$ & $38.38 \pm 9.78$ & -3.69 & $<.01^{*}$ \\
$(\mathrm{~mm} / \mathrm{s})$ & Close & $64.59 \pm 14.33$ & $71.52 \pm 14.68$ & -2.32 & $.03^{*}$ \\
\hline
\end{tabular}

$* \mathrm{p}<.05$ 
Previous studies found that fatigue to the plantar flexors and dorsiflexors of the ankle created significant increases in postural sway (Lundin et al., 1993; Yaggie and Mcgregor., 2002), but Adlerton et al. (2003) found no relationship between fatigue to calf musculature and single-leg balance immediately after a continuous heelraising task. On the one hand, Corbeil et al. (2003) observed similar destabilizing effects of muscular fatigue with and without vision. Ledin et al. (2004) showed that vision was able to substantially limit, along the antero-posterior axis mainly, the increased postural sway induced by the calf muscles fatigue.

In our study, the fatigue of the calf muscle produced significant changes in postural balance during single leg standing. These results might suggest that the function of the calf muscle in single-leg stance are important to maintain the postural stability as like other ankle muscles that effected by the fatiguing tasks.

This study has several limitations that need to be considered when interpreting the results. This study could not be normalized because of a fairly small sample size. It is therefore not possible to determine how much of the difference of measurement were exact. However, there were significant differences between before and after the calf muscle fatigue feeling in all the measured parameters, which can be considered of great importance for these subjects. Further studies are needed to investigate how can prevent the muscle fatigue during clinical interventions for postural balance and to see if there are any difference both eye open and close conditions in the lower extremity exercise. This study also included only healthy younger adults, and future studies need to evaluate in various an age populations.

\section{Conclusion}

This study suggested that calf muscle fatigue has affected on postural balance when standing one leg both eye open and close conditions and postural control was disturbed by muscle fatigue and visual feedback in single-legged standing.

\section{Acknowledgements}

This research was supported by Kyungsung University Research Grants in 2017.

\section{References}

Adlerton AK, Moritz U, Nissen RM. Forceplate and accelerometer measures for evaluating the effect of muscle fatigue on postural control during one-legged stance. Physiother Res Inter 2003;8(4):187-99.

Allen DG, Lamb GD, Westerblad H. Skeletal muscle fatigue: Cellular mechanisms. Physiol Rev. 2008;88(1): $287-332$

Boucher JA, Abboud J, Descarreaux M. The influence of acute back muscle fatigue and fatigue recovery on trunk sensorimotor control. J Manupulative Physiol Ther. 2012;35:662-8.

Corbeil P, Blouin JS, Begin F, et al. Perturbation of the postural control system induced by muscular fatigue. Gait Posture. 2003;18:92-100.

Egana M, Green S. Intensity-dependent effect of body tilt angle on calf muscle fatigue in humans. Eur J Appl Physiol. 2007;99:1-9.

Forestier N, Teasdale N, Nougier V. Alteration of the position sense at the ankle induced by muscular fatigue in humans. Med Sci Sports Exerc. 2002;34:117-22.

Gandevia SC. Spinal and supraspinal factors in human muscle fatigue. Physiol Rev. 2001;81:1725-89.

Green S, Mehlsen J. Peripheral arterial disease. In: Saltin B, Boushel R, Secher N, Mitchell J (eds) Exercise and circulation in health and disease. Human Kinetics, 
Champaign. 1999.

Gribble PA, Hertel J. Effect of hip and ankle muscle fatigue on unipedal postural control. J Electromyo Kinesio. 2004;14:641-6.

LaRoche DP, Cremin KA, Greenleaf B, et al. Rapid torque development in older female fallers and nonfallers: a comparison across lower-extremity muscles. J Electromyogr Kinesiol. 2010;20(3):482-8.

Kwon OS, Lee SW, Seo DK, et al. The effects of exercise-induced fatigue on knee joint position sense in the young, elderly adults and stroke patients. J Korean Soc Phys Med. 2013;8(4):619-25.

Ledin T, Fransson PA, Magnusson M. Effects of postural disturbances with fatigued triceps surae muscles or with $20 \%$ additional body weight. Gait Posture. 2004;19:184-93.

Lundin TM, Feuerbach JW, Grabiner MD. Effect of plantarflexor and dorsiflexor fatigue on unilateral postural control. J Appl Biomech. 1993;9:191-201.

Maritz CA, Silbernagel KG. A prospective cohort study on the effect of a balance training program, including calf muscle strengthening, in community-dwelling older adults. J Geriatr Phys Ther. 2016;39:125-31.

Önell A. Quantifying Human Balance. Analysis of Force plate
Data. Doctor's Degree. Uppsala University. 1999. Rougier PR. Undisturbed stance control in healthy adults is achieved differently along anteroposterior and mediolateral axes: evidence from visual feedback of various signals from center of pressure trajectories. J Mot Behav. 2009;41:197-206.

Vuillerme N, Forestier N, Nougier V. Attentional demands and postural sway: the effect of the calf muscles fatigue. Med Sci Sports Exerc. 2002;34(12):1907-12

Vuillerme N, Burdet C, Isableu B, et al. The magnitude of the effect of calf muscles fatigue on postural control during bipedal quiet standing with vision depends on the eye-visual target distance. Gait Posture 2006;24:169-72.

Yaggie JA, Mcgregor SJ, Effects of isokinetic ankle fatigue on the maintenance of balance and postural limits. Arch Phys Med Rehabil. 2002;8:224-8.

Yun CK, Yoo JN. The effects of visual biofeedback balance training on functional activity in children with cerebral palsy: A pilot study. J Korean Soc Phys Med. 2016;11(3):133-9.

Zijlstra A, Mancini M, Chiari L, et al. Biofeedback for training balance and mobility tasks in older populations: a systematic review. J Neuroeng Rehabil. 2010;7:58. 
